\title{
Economic and environmental evaluation of coal production in China and policy implications
}

\author{
Li Li $\cdot$ Yalin Lei $\cdot$ Dongyang Pan
}

Received: 25 July 2014 / Accepted: 3 February 2015/Published online: 25 February 2015

(C) The Author(s) 2015. This article is published with open access at Springerlink.com

\begin{abstract}
Coal takes up an important position in China's energy structure. The relationship between coal resource, economic growth and environment protection has been in focus in recent research. However, both research methods and research scope need to be expanded to promote the practical effects of research results, especially studies concerning China's situation. Here we present a detailed basis for policy making with the following objectives: (1) to examine the relationship between coal development and economic growth in China with multiple linear regression model, using the data from 1997 to 2010 and the indices of the output of raw coal, the gross value of coal industrial output, the new investment in fixed assets of coal, gross domestic product and the gross value of industrial output and (2) to measure the environmental loss caused by coal mining and washing with the given model of environmental damage cost based on the data of 2010 and the indices of waste water, waste gas, waste residues, crop loss, land resource and soil deterioration. The research results show that there is a significant positive correlation between coal development and economic growth in China. The total environmental loss in coal mining and washing in 2010 took up approximately $2.7 \%$ of the average price of coal. Our study recommends that Chinese government and coal companies should (1) keep moderate speed in coal production; (2) increase investment in technology innovation so as to reduce the environmental damage; and (3) increase environment tax.
\end{abstract}

Keywords Coal production - Economic growth - Environmental loss - Multiple linear regression · Environmental damage cost model

L. Li · Y. Lei (ه)

School of Humanities and Economic Management, China University of Geosciences, 29 Xueyuan Road, Haidian District, Beijing 100083, China

e-mail: leiyalin@cugb.edu.cn

L. Li · Y. Lei

Key Laboratory of Carrying Capacity Assessment for Resource and Environment, Ministry of Land and Resource, Beijing 100083, China

D. Pan

Central University of Finance and Economics, Beijing 100081, China 


\section{Introduction}

Coal is one of the most important energy resources in the world. Coal resources have occupied a strategic position in national economy and residents' life in China. According to China Statistical Yearbooks 1997-2010, the coal resource makes up about $77 \%$ in energy production and about $69 \%$ in energy consumption (National Bureau of Statistics 1998-2011). Coal resources are predicted to account for about $50 \%$ in energy consumption in 2030 in spite of the development of renewable energy (Zhongyannet 2014). Even though coal resources continue to impact China's economic growth, carbon, sulfur, ash from coal will pollute environment, through waste water (WW), waste gas (WG), coal gangue, tailings, dust and volatile gas.

Several investigations have been carried out on energy development, such as on coal development, electricity development (Zheng et al. 2014; Mustafa and Merih 2014; Gutiérrez et al. 2006) and new energy industries (Paddy and Colin 2014). The relationships among coal development, economic growth and environmental damage have attracted much attention.

However, no consistent results have been achieved on the relationship between coal development and economic growth. Seung-Hoon (2006) noted that there was a bidirectional causality between coal consumption and economic growth in Korea by applying modern time-series techniques. Nicholas and James (2010a, b) used a multivariate panel framework based on the data from 1980 to 2006 and found that bidirectional causality existed between coal consumption and economic growth in both the short and long run in 15 emerging market economies. Subsequently, Nicholas and James (2010a, b) used the same model and the panel data for 1980 to 2005 to examine the relationship between coal consumption and economic development in 25 OECD countries. The results showed a bidirectional causal relationship between the two in both the short and long run. Harry et al. (2012) proved that unidirectional causality existed in which coal consumption promoted the economic output in both short and long run under the supply-side analysis, whereas there was also unidirectional causality running from income to coal consumption in the short and long run under the demand-side analysis using co-integration and vector error correction model and the data from 1960 to 2008 in China. By utilizing Granger causality tests and the data of the period of 1980-2005, Li et al. (2008) discovered that the series were not co-integrated which indicated that no relationship could be found between coal consumption and economic development in USA. Also, no causality relationship existed between coal consumption and economic development in South Africa, India and South Korea, whereas unidirectional causality existed running from GDP to coal consumption in Japan and China. Yemane (2010) found that a bidirectional causality existed between coal consumption and economic development in South Africa and the USA, a unidirectional causality existed running from economic growth to coal consumption in China and South Korea, and a unidirectional causality existed running from coal consumption to economic growth in India and Japan with VAR framework for the period 1965-2005. Li and Guy (2012) discovered that bidirectional causality existed between coal consumption and GDP in the Coastal and Central regions, but causality was unidirectional from GDP to coal consumption in the Western region by causality tests during the period 1985-2008.

Some workers investigated from the perspective of the relationship between coal production and economic growth. Taking the data of Inner Mongolia during the period from 1988 to 2009, Sun and Yang (2011) used econometrics model and carried on the cointegration test of coal production and coal demand in Inner Mongolia. Their research 
showed that there was co-integration relationship between coal production, GDP of Inner Mongolia and coal consumption. Ge and Lei (2013) applied the multiplier decomposition with the incorporation of the Foster, Greer and Thoerbecke poverty measure to evaluate the impacts of mining development on household income and poverty alleviation in China. One of the results was that the coal sector (coal production) contributed most to income growth and poverty alleviation. Qi and Guo (2013) used Granger test to study the relationship between coal production and economic growth and environmental pollution with Shanxi Province as an example. The results indicated that there was bidirectional causality between coal production and economic growth in Shanxi Province, whereas there was unidirectional causality running from economic growth to coal production in China.

As to the influence of coal development on the environment, previous studies mainly focused on recognizing the pollutions which were caused by coal mining (Yu and Wei 2012; Chen and Chen 2010). Earle and Robert (1996) concluded that both coal mining and coal utilization brought about ecological imbalance. Malcolm and James (2010) argued that China might demand much more coal resource and emit much larger volumes of $\mathrm{CO}_{2}$ than forecasted by many international energy agencies. Bian et al. (2010) recognized that the environmental challenges from coal mining should include coal mine accidents, land subsidence, damage to the water environment, mining waste disposal and air pollution and a conceptual framework for solving mine environmental issues was proposed based on their results that about $39 \%$ of the methane was emitted into the atmosphere and more than $70 \%$ of the mined lands were reclaimed for agricultural purposes in China.

Harry et al. (2012) and Govindaraju and Tang (2013) showed that the amount of $\mathrm{CO}_{2}$ increased along with the growth of coal consumption. Chaulya et al. (2002) calculated emission rates of suspended particulate matter (SPM) from different types of opencast coal mining activities with some major influential parameters. Bian et al. (2009) took Yanzhou coalfield as an example to analyze the effect of mining on the environment. Qi and Guo (2013) tested that coal production brought about WG, sulfur dioxide and solid waste in Shanxi Province. Li and Liu (2006) measured the ecological and environmental damage in the northern Shaanxi Province caused by coal mining in 2003 using the model of environmental damage cost. The results showed that the environmental loss caused by coal mining and washing was about 36.23 RMB per ton. Qin (2009) recognized the ecological environment loss coal mining brought to coal mining area which included soil deterioration, vegetation deterioration, WW, WG, heavy metal pollution, water soil erosion and land desertification and concluded that the eco-compensation costs in Huainan coal mining region was about 19.44 RMB per ton using the model of environmental damage cost during the period from 2008 to 2073.

From the literature above, we may draw some conclusions as follows:

1. No consistent conclusions have been achieved on the relationships between coal development and economic growth (Table 1). Different workers obtained contrasting results when different regions were analyzed for different time spans. It is necessary to make specific studies according to China's real situation because it is hard to choose the existing research results to guide China's practice.

2. As to the research methods on the relationship between coal development and economic growth, it can be found that many researchers use the models which only inspect the direct relationships among the variables that have been already designed in the model, while no hierarchical relationship has been detected.

3. Many scholars have recognized that the pollutions caused by coal development and detailed results have been presented, especially for provincial areas. However, few 


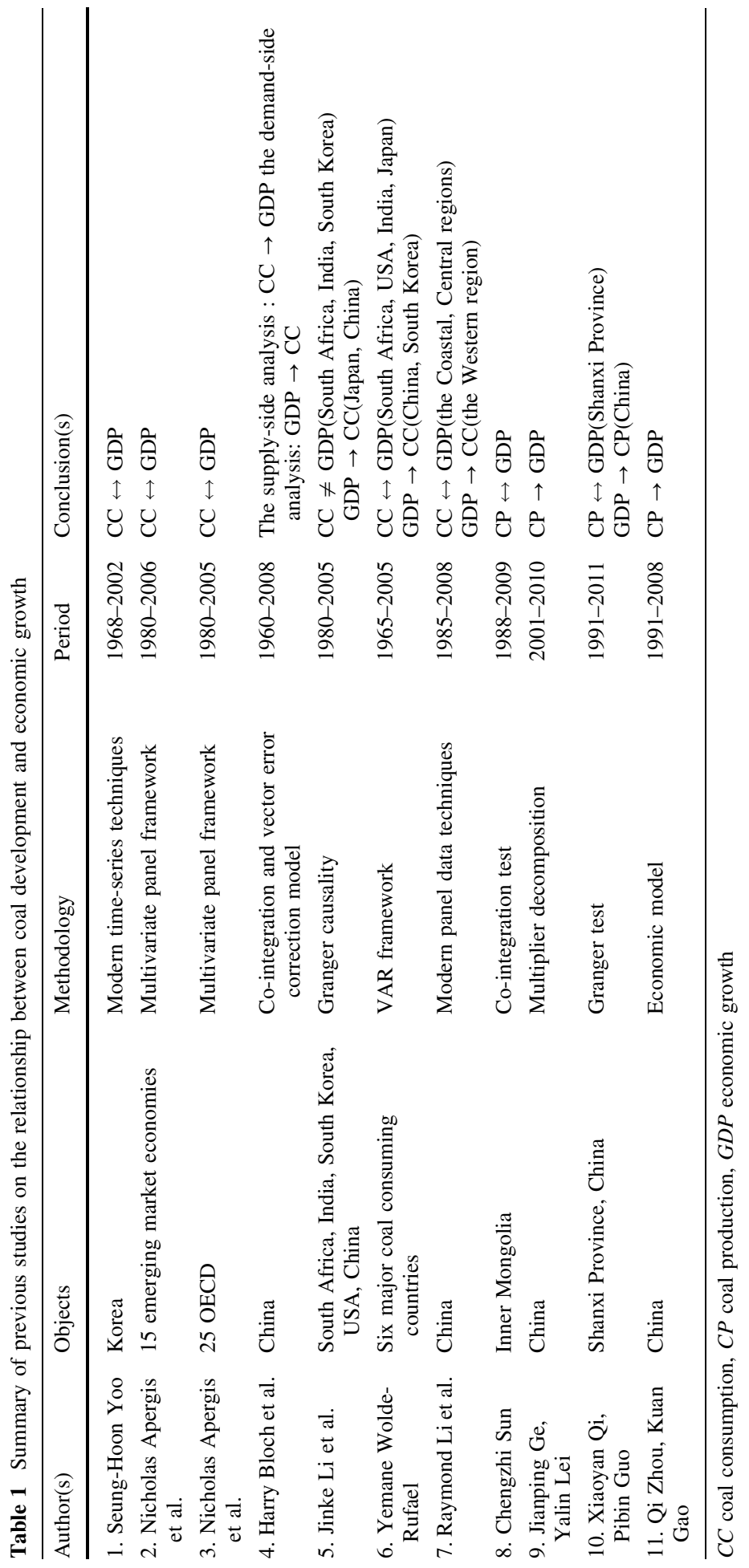


studies have taken the whole region of China as the research objective when calculating the environmental damage cost.

Based on the understanding above, this paper aims to investigate the relationships between coal development and economic growth in China by multiple linear regression model in which deeper relationships may be found with stepwise regression. Furthermore, environmental damage cost is calculated in the general scope of whole China for a better understanding of the degree of environmental damage in the Nation's coal development. Finally, policy suggestions are proposed based on the research results.

The study may serve as a supplementary in research scope and method to the former studies on the relationship between coal development and economic growth. More indices such as the output of raw coal (RCO), the gross value of coal industrial output (GCIOV), the new investment in fixed assets of coal (CFANI), gross domestic product (GDP), the gross value of industrial output (GIOV) are designed to measure the relationship between coal development and economic growth with multiple linear regression model in this paper. Calculation of environmental damage cost will provide more bases for Chinese government to make coal developing and environmental protection policies.

\section{Methods and data}

\subsection{Methods}

\subsubsection{Multiple linear regression models}

As discussed in the introduction above, we apply multiple linear regression model in this paper.

Regression is a common method for investigating the statistical relationship between quantitative variables, which explains the relationship with an equation. The variables in regression model do not necessarily be the time-series data. Correlation of each factor can be measured accurately in regression analysis. There are many methods in regression analysis. Multiple linear regression is one of them and is used to examine the relationship between one dependent variable and two or more independent variables. In studying the actual economic problems, the change of the dependent variable is often influenced by several important factors and multiple linear regression analysis method is then more suitable for choosing more relevant factors as the independent variables to explain the change of the dependent variable. Therefore, multiple linear regression model and stepwise regression analysis method are adopted in this paper.

According to the sample data to estimate the parameters of the model, multiple linear regression uses regression model to determine which independent variables are significant in the model (Viv et al. 2003), where forward regression, backward regression and stepwise regression are included. Forward regression is a method in which a variable will not be rejected once it is chosen in the model. The explanation of some variables tends to become less significant in this situation. Backward regression is a method in which a variable will be excluded forever once it is rejected in the model. Stepwise regression is a combination of forward regression and backward regression, which is often used to select the variables which are relevant to dependent variables. Thus, stepwise regression analysis method is suitable to be used here. 


\subsubsection{The measurement model of environmental damage cost}

Concerning the environmental damage caused by coal development, the environmental value loss caused by coal development is calculated. Here the measurement model of environmental damage cost (Viv et al. 2003) and environmental direct calculation method (Zhong 2012) are utilized to estimate the environmental loss caused by coal development. In the process of coal mining and washing, utilization, transportation and burning, serious damage is brought to the environment, especially in the stage of coal mining and washing. In this study, we only calculate the environmental loss caused by coal mining and washing due to the limited data and the length limit of the paper.

\subsection{Indices and data}

Coal production is always decided by coal consumption, whereas coal production also affects coal consumption with the mediation of coal price in turn, so that the balance ultimately appears. Coal production is supposed to be equal to coal consumption, so the relationships between coal development and economic growth are to be discussed in general rather than the discussion on coal production and economic growth, coal consumption and economic growth, respectively.

To further detect the hierarchical relationships, GDP and GIOV are chosen as the indices of economic growth; RCO, GCIOV, and CFANI are chosen as the indices of coal development. We realize that the data, such as coal production, are usually stated with differences but without specifying the reasons from different sources. To keep consistency, the relevant data are taken from China Statistical Yearbook 1997-2010, China Coal Industry Yearbook covering the period from 1997 to 2010. By referring to many relevant studies and based on environmental economics, the measurement model of environmental damage cost is used to evaluate the environmental cost caused by coal development. We also adopt direct calculation method to measure it (Wang et al. 2005). The environmental pollution and damage caused by coal mining are analyzed in three parts according to the three main pollutions. The first part explains "the three wastes" and theirs calculation, the second part introduces land subsidence calculation, and the third part describes how soil deterioration is measured. Thus, five indices are adopted when evaluating the environmental loss of coal mining and washing, in which WW, WG, WR, LR and SD are from China Statistical Yearbook on Environment 2011 and China Environment Yearbook 2010.

\section{Theoretical Models}

\subsection{Model on the relationship between coal development and economic growth}

To analyze the relationship between coal development and economic growth with multiple linear regression model, a linear relationship between dependent variable $\mathrm{Y}$ and two or more independent variables $X_{1}, X_{2}, \ldots, X_{k}$ has to be presumed. Then

$$
\mathrm{Y}=\beta_{0}+\beta_{1} \mathrm{X}_{1}+\beta_{2} \mathrm{X}_{2}+\ldots \beta_{\mathrm{K}} \mathrm{X}_{\mathrm{k}}+\mu
$$

where $Y$ is dependent variable, $X_{j}(j=1,2, \ldots, \mathrm{k})$ is the $j$ independent variable, $\beta_{j}(j=0,1$, $2, \ldots, k)$ is the $k+1$ unknown parameter, and $\mu$ is stochastic error. 
In the choice of the independent variable $X_{i}$, first the paper chooses some explanatory variables from the factors relating to coal development which may influence the dependent variable $Y$. At the same time, the method of stepwise regression analysis is chosen to ensure which independent variable can be adopted in the equation. One or some independent variables may have little effect on dependent variable $Y$. In such conditions, the choice of the independent variable $X$ may be influence on the regression equation which will be established in the next step.

Secondly, GDP and GIOV are chosen as dependent variables so as to quantify economic growth. That is to say, two regression analyses will be done to find out the relationship between coal development and economic growth, one is regression analysis among RCO, GCIOV, CFANI and GDP, and the other is among RCO, GCIOV, CFANI and GIOV. Then appropriate independent variables may be found out from the variables above which have been chosen.

\subsection{Model on environmental loss calculation}

According to China Statistical Yearbook on Environment 2011, the total volume of industrial WW discharged came to 21,185.85 million tons in 2010, and coal mining and washing accounted for about $4.9 \%$; the industrial WG emission reached 519,167 million cubic meters, and coal mining and washing accounted for about $0.45 \%$; the industrial solid wastes generated amounted to 2251 million tons, in which coal mining and washing accounted for $12.14 \%$. The environmental problem brought about by coal mining and washing has been affecting many aspects and causing a certain degree of damage to economics and society.

With the latest available data from China Statistics Yearbook on Environment 2011 (National Bureau of Statistics and Ministry of Environmental Protection 2011), China Coal Industry Yearbook 1997-2010 (China Coal Industry Yearbook Editorial Department 19982011), China Mining Yearbook 2011 (China Mining Yearbook Editorial Department 2012), the true cost of coal (Mao et al. 2008) and notice on issuing the execution plan of the minimum purchase price of wheat in 2008, 2009, 2010 (National Development and Reform Commission 2008, 2009, 2010), the environmental loss caused by coal mining and washing in China in 2010 was estimated. The model of estimating the loss of environmental pollution is

$$
C=C_{1}+C_{2}+C_{3}
$$

In this equation, $C$ is the total environmental loss of coal mining and washing, $C_{1}$ represents the loss of environment made by the three wastes, $C_{2}$ indicates the loss of environment made by land subsidence, and $C_{3}$ shows the loss of environment made by soil deterioration.

\subsubsection{Three wastes}

The loss of environment made by the three wastes $C_{1}$ is summed up by $C_{\mathrm{WW}}, C_{\mathrm{WG}}$ and $C_{\mathrm{WR}}$, which, respectively, indicates the environmental loss brought out by WW, WG and WR. The model is

$$
C_{1}=C_{\mathrm{WW}}+C_{\mathrm{WG}}+C_{\mathrm{WR}}
$$




\section{WW}

Waste water in coal mining mainly comes from two sources. One is from the water level decreasing and the serious loss of water and soil in mining area (Wang and Chen 2007), and the environment loss of which is $C_{\mathrm{WW} 1}$. According to the statistical data, in the main mining areas, there is approximately $71 \%$ mining areas in water shortage (Mao et al. 2008). The other is mine water, and the environment loss of it is $C_{\mathrm{WW} 2}$.

$$
\begin{aligned}
C_{\mathrm{WW}} & =C_{\mathrm{WW} 1}+C_{\mathrm{WW} 2} \\
& =P \times R_{1}+P \times Q_{2}
\end{aligned}
$$

In this equation, $P$ is per external cost caused by water pollution, $R_{1}$ is the number of people suffering from water shortage in mining area, and $Q_{2}$ is the total amount of waste discharged.

\section{WG}

Waste gas of coal mining mainly comes from coal bed methane and coal gangue release, industrial soot, $\mathrm{SO}_{2}$, dust.

$$
C_{\mathrm{WG}}=\sum\left(Q_{i} \times P_{\mathrm{wg}}\right)
$$

where $Q_{i}$ represents the emission of four waste gas and $P_{\mathrm{wg}}$ is the unit cost of external environmental controlling of WG.

\section{WR}

Waste residues (WR) mainly include the place of coal gangue and coal ash, namely $Q_{3}$ is the quantity that industrial solid wastes generated minus industrial solid wastes utilized, and $P_{3}$ is the treatment cost of WR.

$$
C_{\mathrm{WR}}=Q_{3} \times P_{3}
$$

\subsubsection{Land subsidence}

The environmental loss of land subsidence in coal mining $C_{2}$ largely comes from the compensation of crop loss $C_{\mathrm{CL}}$, the loss fee of land resource $C_{\mathrm{LR}}$ and the compensation fee of the resettlement $C_{\mathrm{R}}$.

$$
C_{2}=C_{\mathrm{CL}}+C_{\mathrm{LR}}+C_{\mathrm{R}}
$$

1. $C_{\mathrm{CL}}$

Using the market value method, the compensation of CL should be equaled to the economic loss caused by the change of land quality, the loss of the output and the price of crops.

$$
C_{\mathrm{CL}}=S_{\mathrm{C}} \times T \times V
$$

$S_{\mathrm{c}}$ is the new subsidence of cultivated land in the land subsidence area, and T shows the length of the compensation period, which is generally 5 years. $V$ expresses crop production of every hectare. 
2. $C_{\mathrm{LR}}$

According to the market price, the loss fee of land resource $C_{\mathrm{LR}}$ is calculated, which may be counted by applying the fee increased for cultivated lands. Non-cultivated lands can be counted in accordance with the fees of recovery and administration.

$$
C_{\mathrm{LR}}=P_{1} \times S_{1}+P_{2} \times S_{2}
$$

where $P_{1}$ indicates the reclamation fee of cultivated lands per hectare, $S_{1}$ is the area of cultivated lands, $P_{2}$ represents the reclamation fee of non-cultivated lands per hectare, and $S_{2}$ is their area.

3. $C_{\mathrm{R}}$

The compensation fee of the resettlement for land destruction is usually paid by government and coal enterprise together. Its calculation model is relatively simple as below:

$$
C_{\mathrm{R}}=E \times R
$$

The price of $E$ was represented by the highest resettlement subsidy standard in 2010, and $R$ was the number of the resettlement people.

\subsubsection{Soil deterioration}

Soil deterioration represents the amount of the three waste materials and poisonous substances that invaded into the soil which exceeded the capacity of soil self-purification, making the composition, structure and function of soil to reach a certain extent (Gan et al. 1987). The traits of soil deterioration are persistent and long term (Wang et al. 1987). The toxic heavy metal mercury in the WW in coal mining and washing could also cause heavy damage to the farmland.

$$
C_{3}=P \times M
$$

where $M$ is the weight of mercury and $P$ is the loss caused by per ton of mercury.

\section{Calculation}

4.1 The relationship of coal development and economic growth

With the indexes RCO, GCIOV, CFANI as independent variables and GDP as dependent variable, stepwise regression analysis is taken to perform the first regression analysis and the results are listed in Tables 2, 3, 4 and 5.

Table 2 presents the fitting circumstance of the model. It can be seen that the multiple correlation coefficient $\mathrm{R}$ between the independent variable GCIOV and the dependent

Table 2 Model summary

\begin{tabular}{lllll}
\hline Model & $R$ & $R^{2}$ & Adjusted $R^{2}$ & Standard error of the estimate \\
\hline 1 & $.985^{\mathrm{a}}$ & .969 & .967 & 19338.201 \\
2 & $.996^{\mathrm{b}}$ & .991 & .990 & 10721.023 \\
\hline
\end{tabular}

a Predictors: (constant), GCIOV

b Dependent variable: (constant), GCIOV, RCO 
Table 3 ANOVAc

a Predictors: (constant), GCIOV

b Dependent variable: (constant), GCIOV, RCO

c Dependent variable: GDP

\begin{tabular}{llrllll}
\hline \multicolumn{2}{l}{ Mode } & $S$ & $D f$ & $\begin{array}{l}\text { Mean } \\
\text { square }\end{array}$ & $F$ & Sig. \\
\hline 1 & Regression & $1.414 \mathrm{E} 11$ & 1 & $1.414 \mathrm{E} 11$ & 378.194 & $.000^{\mathrm{a}}$ \\
& Residual & $4.488 \mathrm{E} 9$ & 12 & $3.740 \mathrm{E} 8$ & & \\
& Total & $1.459 \mathrm{E} 11$ & 13 & & & \\
2 & Regression & $1.447 \mathrm{E} 11$ & 2 & $7.233 \mathrm{E} 10$ & 629.261 & $.000^{\mathrm{b}}$ \\
& Residual & $1.264 \mathrm{E} 9$ & 11 & $1.149 \mathrm{E} 8$ & & \\
Total & $1.459 \mathrm{E} 11$ & 13 & & & \\
\hline
\end{tabular}

Table 4 Regression coefficient ${ }^{\mathrm{a}}$

\begin{tabular}{|c|c|c|c|c|c|c|}
\hline & \multirow[t]{2}{*}{ Model } & \multicolumn{2}{|c|}{ Unstandardized coefficients } & \multirow{2}{*}{$\begin{array}{l}\text { Standard } \\
\text { coefficients } \\
\text { Beta }\end{array}$} & \multirow[t]{2}{*}{$T$} & \multirow[t]{2}{*}{ Sig. } \\
\hline & & $B$ & $\begin{array}{l}\text { Standard } \\
\text { error }\end{array}$ & & & \\
\hline \multirow[t]{2}{*}{1} & (Constant) & 87841.077 & 7216.911 & & 12.172 & .000 \\
\hline & GCIOV & 15.306 & 0.787 & .985 & 19.447 & .000 \\
\hline \multirow[t]{3}{*}{2} & (Constant) & -6792.290 & $18,312.794$ & & -.371 & .718 \\
\hline & GCIOV & 9.336 & 1.209 & .600 & 7.723 & .000 \\
\hline & $\mathrm{RCO}$ & 6407.524 & 1209.984 & .412 & 5.296 & .000 \\
\hline
\end{tabular}

a Dependent variable: GDP

Table 5 Variable removed ${ }^{\mathrm{c}}$

\begin{tabular}{llrlll}
\hline Mode & Beta In & $t$ & Sig. & Partial correlation & $\begin{array}{l}\text { Collinearity statistics } \\
\text { Tolerance }\end{array}$ \\
\hline 1 RCO & $.412^{\mathrm{a}}$ & 5.296 & .000 & .848 & .130 \\
CFANI & $.110^{\mathrm{a}}$ & .340 & .740 & .102 & .027 \\
$2 \mathrm{CFANI}$ & $.064^{\mathrm{b}}$ & .357 & .728 & .112 & .027 \\
\hline
\end{tabular}

a Predictors: (constant), GCIOV

b Dependent variable: (constant), GCIOV, RCO

c Dependent variable: GDP

variable GDP is 0.985 , which indicates that GCIOV is highly relevant with GDP. $R^{2}$ is 0.969 , showing that the regression model is consistent with the data very well. Adjusted $R^{2}$ is 0.967 , which is closer to $R^{2}$, demonstrating the model to be more reliable. Accordingly, the multiple correlation coefficient $R$ among the independent variable GCIOV, RCO and the dependent variable GDP is 0.996, which indicates that GCIOV and RCO are highly relevant to GDP. $R^{2}$ is 0.991 , showing that the regression model fits the data very well. Adjusted $R^{2}$ is 0.990 , closer to $R^{2}$, which demonstrates the model more reliable.

As can be seen from Table $3, F$ value of the regression between the independent variable GCIOV and the dependent variable GDP is 378.194 and probability $\rho$ is 0.000 . 
$F$ value and $\rho$ of GCIOV, RCO and GDP are 629.261, 0.000, respectively. In the significant level of 0.05 , it can be considered that linear relationship exists among the dependent variable GDP and the independent variable GCIOV, GDP and GCIOV, RCO.

From Tables 4 and 5, it can be seen that CFANI is rejected and cannot be brought into the equation. And the coefficients and constants of the regression equation can be obtained in Table 3. So with the analysis above, the multiple linear regression equation established is:

$$
y=-6792.290+6407.524 x_{1}+9.336 x_{2}
$$

Next, the second regression analysis is done, and the results are shown in Tables 6, 7, 8 and 9 as following.

Correlation coefficient $R$ between GCIOV and GIOV is $0.980, R^{2}$ is 0.960 , and adjusted $R^{2}$ is 0.957 in Table 6. Correlation coefficient R between GCIOV, RCO and GIOV is $0.996, R^{2}$ is 0.992 , and adjusted $R^{2}$ is 0.990 .

Table 7 shows that $F$ value between GCIOV and GIOV is 289.888 , and probability $\rho$ is 0.000 . $F$ value, probability $\rho$ among GCIOV, RCO and dependent variable GIOV are

Table 6 Model summary

\begin{tabular}{lllll}
\hline Model & $R$ & $R^{2}$ & Adjusted $R^{2}$ & Standard error of the estimate \\
\hline 1 & $.980^{\mathrm{a}}$ & .960 & .957 & 8922.367 \\
2 & $.996^{\mathrm{b}}$ & .992 & .990 & 4263.641 \\
\hline
\end{tabular}

a Predictors: (constant), GCIOV

b Dependent variable: (constant), GCIOV, RCO

Table 7 ANOVA

a Predictors: (constant), GCIOV

b Dependent variable: (constant), GCIOV, RCO

c Dependent variable: GIOV

\begin{tabular}{llrlll}
\hline Mode & $S$ & $D f$ & Mean square & $F$ & Sig. \\
\hline 1 Regression & $2.308 \mathrm{E} 10$ & 1 & $2.308 \mathrm{E} 10$ & 289.888 & $.000^{\mathrm{a}}$ \\
Residual & $9.553 \mathrm{E} 8$ & 12 & $7.961 \mathrm{E} 7$ & & \\
Total & $2.403 \mathrm{E} 10$ & 13 & & & \\
2 Regression & $2.383 \mathrm{E} 10$ & 2 & $1.192 \mathrm{E} 10$ & 655.520 & $.000^{\mathrm{b}}$ \\
Residual & $2.000 \mathrm{E} 8$ & 11 & $1.818 \mathrm{E} 7$ & & \\
Total & $2.403 \mathrm{E} 10$ & 13 & & & \\
\hline
\end{tabular}

Table 8 Regression coefficient ${ }^{\mathrm{a}}$

\begin{tabular}{|c|c|c|c|c|c|}
\hline Model & $\begin{array}{l}\text { Unstandardized coefficients } \\
B\end{array}$ & Standard error & $\begin{array}{l}\text { Standard coefficients } \\
\text { Beta }\end{array}$ & $T$ & Sig. \\
\hline 1 (constant) & 36105.652 & 3329.779 & & 10.843 & .000 \\
\hline GCIOV & 6.183 & 0.363 & .980 & 17.026 & .000 \\
\hline 2 (constant) & -9705.187 & 7282.811 & & -1.333 & .210 \\
\hline GCIOV & 3.293 & 0.481 & .522 & 6.849 & .000 \\
\hline RCO & 3101.803 & 481.198 & .491 & 6.446 & .000 \\
\hline
\end{tabular}

\footnotetext{
a Dependent variable: GIOV
} 
Table 9 Variable removed ${ }^{\mathrm{c}}$

\begin{tabular}{llrlll}
\hline Mode & Beta In & $T$ & Sig. & Partial correlation & $\begin{array}{l}\text { Collinearity statistics } \\
\text { Tolerance }\end{array}$ \\
\hline 1 RCO & $.491^{\mathrm{a}}$ & 6.446 & .000 & .889 & .130 \\
CFANI & $.054^{\mathrm{a}}$ & .148 & .885 & .045 & .027 \\
2 CFANI & $.000^{\mathrm{b}}$ & .000 & .999 & .000 & .027 \\
\hline
\end{tabular}

a Predictors: (constant), GCIOV

b Dependent variable: (constant), GCIOV, RCO

c Dependent variable: GIOV

$655.520,0.000$, respectively. In the premise of the significant level 0.05 , it can be judged that linear relationship exists between GIOV and GCIOV and between GIOV and GCIOV, RCO.

And the same situation is shown in Tables 4 and 5, where CFANI cannot be introduced into Tables 8 and 9. Consequently, the multiple linear regression equation established is:

$$
y=-9705.187+3101.803 x_{1}+3.293 x_{2}
$$

\subsection{Environmental loss}

\subsubsection{Three wastes}

\section{WW}

According to the related standards in 2010 (Mao et al. 2008), $P$ was about $3.7 \mathrm{RMB} /$ ton, $R_{1}$ was the number of people suffering from water shortage in mining area, about 9.719 million people, and $Q_{2}$ was the total amount of wastewater discharged, about 1048 million ton.

$$
\begin{aligned}
C_{\mathrm{WW}} & =C_{\mathrm{WW} 1}+C_{\mathrm{WW} 2} \\
& =P \times R_{1}+P \times Q_{2} \\
& =3913.56
\end{aligned}
$$

Via estimating, the total environmental loss of waste water $C_{\mathrm{Ww}}$ was approximately 3913 million RMB.

\section{WG}

$Q_{i}$ represents the emission of four WG, which were, respectively, 16.64 million tons, 0.116 million tons, 0.160 million tons and 0.150 million tons. $\mathrm{P}_{2}$ is the unit cost of external environmental control of WG and requires 6.1 RMB (Mao et al. 2008).

$$
\begin{aligned}
C_{\mathrm{WG}} & =\sum\left(P_{2} \times Q_{i}\right) \\
& =104.103
\end{aligned}
$$

Thus, the loss of WG reached about 104 million RMB. 


\section{WR}

The weight of WR was $Q_{3}$, about 64.1 million tons. The unit price of dealing with waste residues $P_{3}$ was about 4.9 RMB (Mao et al. 2008).

$$
\begin{aligned}
C_{\mathrm{WR}} & =P_{3} \times Q_{3} \\
& =314.09
\end{aligned}
$$

By calculation, the loss of WR reached around 314 million RMB.

\subsubsection{Land subsidence}

1. $C_{\mathrm{CL}}$

$S_{\mathrm{c}}$ was $87,000 \mathrm{hm}^{2}$ here. And according to the regulation of the land management law, $T$ was generally 5 years (Zhong 2012). $V$ was about 0.047 million $\mathrm{RMB} / \mathrm{hm}^{2}$ (National Development and Reform Commission 2008, 2009, 2010).

$$
\begin{aligned}
C_{\mathrm{CL}} & =V \times S_{\mathrm{c}} \times T \\
& =20445
\end{aligned}
$$

The result of the compensation of CL obtained was approximately 20,445 million RMB.

2. $C_{\mathrm{LR}}$

$P_{1}$ indicated the reclamation fee of cultivated land per hectare, about 0.01 million RMB. $S_{1}$ was the area of cultivated land, $34,851.481$ hectares. $P_{2}$ was about 0.006 million RMB per hectare, and $S_{2}$ was its area, 61,958.189 hectares.

$$
\begin{aligned}
C_{\mathrm{LR}} & =P_{1} \times S_{1}+P_{2} \times S_{2} \\
& =720.264
\end{aligned}
$$

After calculating, the result was about 720 million RMB.

3. $C_{\mathrm{R}}$

Taking the highest resettlement subsidy standard 0.03 million RMB in 2010 as the price of $E$, the number of the resettlement $R$ was about 64,000 .

$$
\begin{aligned}
C_{\mathrm{RCF}} & =E \times R \\
& =1920
\end{aligned}
$$

So the compensation fee of the resettlement for land destruction was around 1920 million RMB.

\subsubsection{Soil deterioration}

According to the standards and statistical calculation, $P$ was about 67 million RMB per ton and there were about 570 tons of mercury in the WW in coal mining and washing in 2010.

$$
\begin{aligned}
C_{3} & =P \times M \\
& =38190
\end{aligned}
$$


By calculating, soil deterioration brought out 38,190 million RMB to crops.

\subsubsection{Total environmental loss}

According to the model of estimating the loss of environmental pollution and the results of $C_{1}, C_{2}$ and $C_{3}$ above, the total loss of environmental pollution brought by coal mining and washing could be summed up as follows:

$$
\begin{aligned}
C= & C_{1}+C_{2}+C_{3} \\
= & 65607 \\
& C / \mathrm{GDP} \\
= & 0.16 \%
\end{aligned}
$$

The results showed that environmental loss brought by coal mining and washing in 2010 reached 65,607 million RMB which accounted $0.16 \%$ of the GDP.

\section{Results, discussion and policy implications}

\subsection{Results and discussions}

\subsubsection{Coal development and economic growth}

The relationships between coal development and economic growth in China have been inspected above by using multiple linear regression models in which deeper relationships have been found with stepwise regression. The results are summarized below.

1. There is a linear relationship between RCO, GCIOV and GDP, which does not exist been between CFANI and GDP, as seen from Tables 2, 3, 4 and 5. Similarly, from Tables $6,7,8$ and 9, it can be judged that there is linear relationship between GIOV and GCIOV and between GIOV and GCIOV, RCO, which is not found between CFANI and GIOV. At the same time, CFANI is rejected and cannot be brought into the multiple linear regression equation obtained in this paper when the relationship is measured between coal development and economic growth.

The reason for CFANI being rejected is probably that CFANI dropped significantly in 1998, 2001 and 2002 which indicated that coal supply exceeded coal demand in those years according to China Coal Industry Yearbook.

2. Bidirectional relationship has not been found among RCO, GCIOV, GIOV and GDP. Hierarchical analysis among the relationship of coal development and economic growth needs to be studied more in the future.

3. Unidirectional relationships run from RCO, GCIOV to GDP and from RCO, GCIOV to GIOV. There is a positive correlation among RCO, GCIOV to GDP as shown in Table 4. The result is in accordance with the studies of Chengzhi Sun, Jianping Ge and Yalin Lei, Xiaoyan Qi and Pibin Guo, Qi Zhou and Kuan Gao, which further suggest that China's economy is promoted by energy consumption to some extent.

Similarly, there is a positive relationship running from RCO, GCIOV to GIOV shown in Table 8 . These results substantiate those from previous research such as those by Lei et al. 
(2013), which showed that coal development may enhance the GCIOV, and it also enhances the relative industrial output.

\subsubsection{Environmental assessment}

\section{The total environmental loss}

By using the model of environmental damage cost and environmental direct calculation method, the total environmental loss caused by coal mining and washing was about 65,607 million RMB, which accounted for $0.16 \%$ of GDP in 2010.

According to the output of RCO in 2010, the environmental loss caused by coal mining and washing was about $20.33 \mathrm{RMB}$ per ton, which accounted for approximately $2.7 \%$ of the average price of coal 753.4 RMB in 2010. This result is close to the results of Qin (2009), who took Huainan coal mining region as an example. However, the result in this paper appeared a bit larger compared with the result of GP Li and ZG Liu, which showed that the environmental loss caused by coal mining and washing in the northern Shaanxi province was about $36.23 \mathrm{RMB}$ per ton in 2003. Two implications may be derived from the comparisons that much progress of environmental protection has been achieved in China in the recent years as compared to the past. Meanwhile, environmental damage was serious in the northern Shaanxi Province since Shaanxi acts as one of the energy bases of China.

2. Three wastes, land subsidence and soil deterioration

According to the computations presented in this paper, the loss of three wastes reached around 4331.753 million RMB in 2010 which took up $6.65 \%$ of total environmental damage cost in coal mining and washing process. The land subsidence was about 23,085.264 million RMB and soil deterioration loss reached 38,190 million RMB, with which together $93.35 \%$ of total environmental damage cost was taken up. We may consider that the destruction of land accounts for the most part of environmental damage loss in the process of coal mining and washing.

\subsection{Policy implications}

Resource, economy and environment constitute an interdependent system, on which humans have been relying for both life and work. As a responsible, big and developing country, China has been making great efforts to cope with the problems in coal developing as well as to keep the economic growth and protect our environment well. Considering the situation that China's energy structure will still be dominated by coal resource for quite a long time in the future, some policy suggestions are proposed based on the results in this paper.

1. Keep moderate speed in the development of coal industry. According to the results achieved in this paper, there are linear relationships from RCO, GCIOV to GDP and from RCO, GCIOV to GIOV. RCO and GCIOV play a promoting role in enhancing GDP and GIOV. Although China is listed the second largest economy in the world in 2013, the GDP per capita of \$5414 still ranked behind 80th in the world. Many remote regions are still at the poverty level nowadays. So keeping moderate economic growth is still an important task for Chinese people and corresponding growth of coal development is still necessary.

2. Increase investment in technology innovation so as to reduce the environmental damage. As shown in the results, land subsidence and soil deterioration compensation 
take up $93.35 \%$ of total environmental damage cost in coal mining and washing. It is urgent for China to promote such technologies as disseminate clean coal technology, coal liquefaction or coal seam gas. It is also a good choice for China to use advanced stoves in heating so as to save coal resource and protect environment.

3. Increase environment tax. As the results shown in this study, the environmental loss caused by coal mining and washing account for approximately $2.7 \%$ of the average price of coal. The environmental loss actually should be much larger if we calculate the cost in coal mining and washing in the overall way. A big part of cost producing in coal transportation and utilization has not been included yet in this paper. So it is necessary to add environment tax if the price composition keeps the same.

Acknowledgments The authors would like to thank anonymous reviewers for their valuable comments and sincerely express thanks for the support from the National Natural Science Foundation of China under Grant No. 71173200 and the support from the Development and Research Center of China Geological Survey under Grant No. 12120113093200. We also would like to give our special thanks to Ms. Huayan Pian, an excellent professional English translator for her help in language editing.

Open Access This article is distributed under the terms of the Creative Commons Attribution License which permits any use, distribution, and reproduction in any medium, provided the original author(s) and the source are credited.

\section{References}

Bian ZF, Dong JH, Lei SG et al (2009) The impact of disposal and treatment of coal mining wastes on environment and farmland. Environ Geol 58:625-634

Bian ZF, Inyang HI, Daniels JL et al (2010) Environmental issues from coal mining and their solutions. Mining Science and Technology 20:0215-0223

Govindaraju VGRC, Tang CF (2013) The dynamic links between $\mathrm{CO}_{2}$ emissions, economic growth in China and India. Appl Energy 104:310-318

Chaulya SK, Chakraborty MK, Ahmad M et al (2002) Development of empirical formulae to determine emission rate from various opencast coal mining operations. Water Air Soil Pollut 140:21-55

Chen GY, Chen C (2010) SPSS 17.0 Chinese version functions commonly used and application examples succinctly. Publishing House of Electronics Industry, Beijing (In Chinese)

China Coal Industry Yearbook Editorial Department (1998-2011) China Coal Industry Yearbook 1997-2010. China Coal Industry Press, Beijing (In Chinese)

China Mining Yearbook Editorial Department (2012) China Mining Yearbook 2011. Seismic Press, Beijing (In Chinese)

Earle AR, Robert E (1996) Environmental effects of mining, vol 43. CRC Press, Boca Raton, pp 49-85

Gan ZG et al (1987) Introduction to environmental economics. Northwestern Polytechnical University Press, Shanxi (In Chinese)

Ge JP, Lei YL (2013) Mining development, income growth and poverty alleviation: a multiplier decomposition technique applied to China. Energy Policy 38:278-287

Gutiérrez R, Gutiérrez-Sánchez R, Nafidi A (2006) Electricity consumption in Morocco: stochastic Gompertz diffusion analysis with exogenous factors. Appl Energy 83:1139-1151

Harry B, Shuddhasattwa R, Ruhul S (2012) Coal consumption, $\mathrm{CO}_{2}$ emission and economic growth in China: empirical evidence and policy responses. Energy Econ 34:518-528

Lei YL, Cui N, Pan DY (2013) Economic and social effects analysis of mineral development in China and policy implications. Resources Policy 38:448-457

Li R, Guy CKL (2012) Coal consumption and economic growth in China. Energy Policy 43:438-443

Li GP, Liu ZG (2006) Ecological and environmental damage in coal exploitation in Northern Shaanxi. J Henan Univ Sci Technol (Soc Sci) 24:74-77 (In Chinese)

Li JK, Song HL, Geng DM (2008) Causality relationship between coal consumption and GDP: difference of major OECD and non-OECD countries. Appl Energy 85:421-429

Malcolm S, James PD (2010) Growing Chinese coal use: dramatic resource and environmental implications. Energy Policy 38:2116-2122 
Mao YS, Sheng H, Sheng FQ (2008) The true cost of coal. China Coal Industry Publishing House, Beijing (In Chinese)

Mustafa CS, Merih AK (2014) Standby electricity consumption and saving potentials of Turkish households. Appl Energy 114:531-538

National Bureau of Statistics (1998-2011). China Statistical Yearbooks 1998-2011. China Statistics Press, Beijing

National Bureau of Statistics and Ministry of Environmental Protection (2011) China Statistics Yearbook on Environment 2011. China Statistics Press, Beijing (In Chinese)

National Development and Reform Commission (2008). Notice on issuing the execution plan of the minimum purchase price of wheat in 2008. http://www.sdpc.gov.cn/zcfb/zcfbtz/2008tongzhi/ t20080520_212076.htm. Accessed 20 May 2008 (In Chinese)

National Development and Reform Commission (2009) Notice on issuing the execution plan of the minimum purchase price of wheat in 2009. http://www.sdpc.gov.cn/zcfb/zcfbtz/2009tz/t20090521_280627. htm. Accessed 21 May 2009 (In Chinese)

National Development and Reform Commission (2010). Notice on issuing the execution plan of the minimum purchase price of wheat in 2010. http://www.sdpc.gov.cn/zcfb/zcfbtz/2010tz/t20100526_ 348861.htm. Accessed 26 May 2010 (In Chinese)

Nicholas A, James EP (2010a) Coal consumption and economic growth: evidence from a panel of OECD countries. Energy Policy 38:1353-1359

Nicholas A, James EP (2010b) The causal dynamics between coal consumption and growth: evidence from emerging market economics. Appl Energy 87:1972-1977

Paddy F, Colin F (2014) Demand side management of industrial electricity consumption: promoting the use of renewable energy through real-time pricing. Appl Energy 113:11-21

Qi XY, Guo PB (2013) Study on the relationship among coal production and economic growth and environmental pollution - Taking Shanxi Province as an example. China mining magazine 22:41-45 (In Chinese)

Qin G (2009) Study on the ecological environmental compensation mechanism in coal mining regions. China University of Mining and Technology, Jiangsu Province (In Chinese)

Seung-Hoon Y (2006) Causal relationship between coal consumption and economic growth in Korea. Appl Energy 83:1181-1189

Sun CZ, Yang J (2011) The analysis of coal production and economic growth in Inner Mongolia. China Min Mag 20:28-31 (In Chinese)

Viv B, Liz C, Jonathan B (2003) Statistics review 7: correlation and regression. Crit Care 7:451-459

Wang XL, Chen YJ (2007) Study on environmental impact of coal mining and model discussion-Taking Yulin as an example. Energy Technology and Management 5:94-96 (In Chinese)

Wang EY et al (1987) Cultural geography. Northwestern Polytechnical University Press, Shanxi (In Chinese)

Wang AY, Lei YL, Sha JH (2005) Resource and environmental economics, 1st edn. Geological Publishing House, Beijing (In Chinese)

Yemane WR (2010) Coal consumption and economic growth revisited. Appl Energy 87:160-167

Yu SW, Wei YM (2012) Prediction of China's coal production-environmental pollution based on a hybrid genetic algorithm-system dynamics model. Energy Policy 42:521-529

Zheng ML, Christoph JM, Klaus SL (2014) Agent-based model for electricity consumption and storage to evaluate economic viability of tariff arbitrage for residential sector demand response. Appl Energy 126:297-306

Zhong SH (2012) Study on the environmental cost of coal development. Metallurgical Industry Press, Beijing (In Chinese)

Zhongyannet (2014) Coal will be occupied the leading position in China's energy consumption for a long time in the future. http://www.chinairn.com/news/20140609/160037217.shtml (in Chinese) Accessed 9 June 2014 